\title{
DESENVOLVIMENTO E CARACTERIZAÇÃO QUÍMICA E SENSORIAL DE IOGURTE SEMIDESNATADO ADICIONADO DE CONCENTRADO PROTEICO DE SORO
}

\author{
Development, chemical and sensory characterization of semi \\ skim yogurt added with whey protein concentrate
}

\begin{abstract}
Andressa Regina Antunes ${ }^{I^{*},}$ Luciana Oliveira de Farina ${ }^{1}$, Luciana Bill Mitiko Kottwitz ${ }^{l}$, José Afonso Passotto ${ }^{2}$
\end{abstract}

\begin{abstract}
RESUMO
Objetivou-se com este trabalho realizar a caracterização química e verificar a aceitabilidade de um iogurte semidesnatado adicionado com concentrado proteico de soro (WPC 35 \%) e compará-lo ao iogurte tradicional, sem adição de qualquer fonte proteica. Para isso, foram elaboradas duas formulações: 1 - semidesnatado tradicional, e 2 - semidesnatado adicionado com WPC 35 \%, com posterior avaliação das características físico-químicas de acidez, $\mathrm{pH}$ e viscosidade, bem como as análises composicionais dos teores de umidade, sólidos totais, cinzas, proteínas, gorduras e carboidratos de ambas as formulações. A análise sensorial foi realizada com 80 provadores não treinados, os quais tiveram como parâmetros de avaliação os aspectos de aparência, sabor, aroma e consistência. Os parâmetros aparência e consistência apresentaram diferença significativa entre as notas recebidas, sendo o iogurte adicionado com WPC $35 \%$ o mais preferido nestes aspectos e com maior aceitação geral entre os provadores. Os resultados indicam que o uso de WPC 35 \% em alimentos é uma alternativa promissora, considerando a aceitabilidade geral obtida, o conteúdo proteico benéfico à saúde dos consumidores, à melhoria das características tecnológicas proporcionada aos alimentos aliado à extensão em que é produzido, o baixo custo e à redução do dano causado ao meio ambiente.
\end{abstract}

Palavras-chave: derivado lácteo; resíduo agroindustrial; fonte proteica.

1 Universidade Estadual do Oeste do Paraná (UNIOESTE), Campus de Cascavel, rua Universitária, 2069, Caixa Postal 711, Bairro Jardim Universitário, 85819-110, Cascavel, PR, Brasil. E-mail: antunes. andressa@hotmail.com

2 SOORO Ingredientes LTDA, rodovia BR 163, km 283,8, Marechal Cândido Rondon, PR, Brasil.

* Autor para correspondência.

Recebido / Received: 30/09/2014

Aprovado / Approved: 03/02/2015 


\begin{abstract}
The aim of this work was to develop, to perform the chemical characterization and verify the acceptability of a semi skim yogurt added with whey protein concentrate (WPC $35 \%$ ), and compare it to traditional yogurt, without adding any protein source. For this, two formulations were prepared: 1- traditional semi skim and 2: semi skim added with WPC $35 \%$, with subsequent evaluation of physicochemical characteristics of acidity, $\mathrm{pH}$ and viscosity, as well as the compositional analysis of the levels of humidity, full solids, ash, protein, fat and carbohydrates for both formulations. The sensory analysis was performed with 80 untrained tasters, which was based on parameters of appearance, taste, flavor and consistency. The appearance and consistency parameters showed a significant difference between received grades, and the yogurt added with WPC $35 \%$ the most preferred these aspects, as well as the formulation with the highest widespread acceptance among testers. The results indicate that the use of WPC $35 \%$ in foods is a promising alternative, considering the overall acceptance obtained, the protein content beneficial to the consumers health, the improvement of technological properties provided to food coupled to the extent which it is produced, low cost and reducing the damage caused to the environment.

Keywords: milk derived; agroindustrial residue; source protein.
\end{abstract}

\section{INTRODUÇÃO}

Segundo a legislação brasileira (BRASIL, 2007), iogurte é o produto obtido por meio da adição ou não de outras substâncias alimentícias, produzidos por coagulação e diminuição do $\mathrm{pH}$ do leite ou reconstituído, adicionado ou não de outros produtos lácteos, através de fermentação lática mediante ação de cultivos de Streptococcus thermophilus e Lactobacillus bulgaricus, aos quais se podem acompanhar, de forma complementar, outras bactérias ácido-láticas, que por sua atividade, contribuem para a determinação das características do produto final.

Uma alternativa aplicável ao processo produtivo, que possui a finalidade de favorecer o consumo, aprimorar as características tecnológicas e, consequentemente, a aceitação deste derivado lácteo, é o aumento da matéria sólida utilizada, que pode ser feita através da adição de leite em pó, ou de outros derivados lácteos, como por exemplo, o soro em pó (RAMOS et al., 2009; COELHO; GIGANTE, 2010; LEINDECKER, 2011).
O concentrado proteico de soro (CPS), ou whey protein concentrate (WPC), como também é conhecido, consiste em um sistema multifuncional proveniente da indústria de laticínios, que pode ter o seu conteúdo proteico em concentrações que variam de $35 \%$ a $90 \%$ (PAGNO, 2009). É obtido pela separação parcial das proteínas do soro de leite através de processos de ultrafiltração por membranas, com posterior concentração por evaporação a vácuo, seguido da desidratação pelo processo tipo spray dryer. Após este processamento, as proteínas mantêm as suas propriedades, conferindo valor nutricional e funcional elevado aos produtos em que forem adicionadas (SOORO, 2013). Este coproduto, por sua vez, pode ser incorporado em diversos tipos de alimentos com o objetivo de modificar algumas propriedades por conferir gelatinização, aumento de viscosidade, estabilização de emulsões ou espumas, ampliação da vida de prateleira, entre outras características interessantes (ANTUNES, 2003; PAGNO, et al., 2009). 
Além do aumento do suprimento de aminoácidos essenciais, como os de cadeia ramificada e do conteúdo em peptídeos bioativos, ao agregar as proteínas do soro na alimentação diária quando associada à prática de exercícios físicos, pode gerar um efeito benéfico frente ao anabolismo muscular esquelético, à redução de gordura corporal, entre outros benefícios para a saúde, incluindo efeitos hipotensivo, antioxidante e hipocolesterolêmico (HARAGUCHI et al., 2006; CREDIDIO, 2008).

$\mathrm{O}$ aproveitamento deste resíduo agroindustrial visa ainda reduzir o impacto ambiental causado pelo seu descarte ao meio ambiente (GHALY; KAMAL, 2004), uma vez que o soro de leite é muito poluente, requerendo alta demanda bioquímica de oxigênio (DBO) para a sua decomposição, como descrito por Antunes (2003).

O objetivo principal deste trabalho foi desenvolver um iogurte semidesnatado, sabor morango com adição de $10 \%$ de WPC $35 \%$, justificado pelos prováveis benefícios à saúde do consumidor, já citados anteriormente. O iogurte desenvolvido foi caracterizado por meio de análises físico-químicas e pela verificação da aceitabilidade sensorial. Além disso, foi comparado ao iogurte tradicional, sem adição de fonte proteica, normalmente consumido pela população em geral.

\section{MATERIAL E MÉTODOS}

\section{Preparo da cultura}

Foi preparada uma solução de leite reconstituído, por meio da dissolução de $24 \mathrm{~g}$ de leite em pó integral Molico da marca Nestlé ${ }^{\circledR}$, o qual foi pesado em balança da marca Bel ${ }^{\circledR}$, modelo 503, em $200 \mathrm{~mL}$ de água mineral. A solução foi aquecida até $85{ }^{\circ} \mathrm{C}$, e posteriormente resfriada a $40{ }^{\circ} \mathrm{C}$ por meio da imersão em banho de água fria. Neste momento, foi adicionado $0,5625 \mathrm{~g}$ da cultura liofilizada LyoFast da marca Sacco ${ }^{\circledR}$, e homogeneizado até completa dissolução, com posterior incubação por quatro horas na incubadora da marca Nova Orgânica ${ }^{\circledR}$, modelo B.O.D., em temperatura de $40-45^{\circ} \mathrm{C}$. Após este período a cultura foi transferida para geladeira comum, permanecendo a $7^{\circ} \mathrm{C}$ até a utilização na produção dos iogurtes.

\section{Formulações dos iogurtes}

As duas formulações de iogurte foram preparadas, artesanalmente, no Laboratório de Alimentos da Universidade Estadual do Oeste do Paraná - UNIOESTE - Campus Cascavel, diferindo entre si apenas na etapa de adição do WPC35 \%, sendo: T1 (tratamento 1) - iogurte semidesnatado tradicional, e T2 (tratamento 2) - iogurte semidesnatado obtido com WPC 35\%. O leite selecionado para a pesquisa possuía em sua constituição $2 \%$ de gordura, conforme o rótulo do produto, enquadrando-se, portanto, como um leite semidesnatado (BRASIL, 2011).

O início do preparo do iogurte controle (T1) se deu por meio da pesagem dos ingredientes com posterior mistura, sob aquecimento em temperatura crescente (de $15^{\circ} \mathrm{C}$ a $85^{\circ} \mathrm{C}$ ) do leite semidesnatado, açúcar ( $8 \%$ ) e estabilizante TECGEM AA073, GemacomTech $^{\circledR}(0,25 \%)$. A homogeneização manual se fez necessária durante não mais do que 20 minutos, até que a temperatura atingisse $85^{\circ} \mathrm{C}$. Neste ponto, o leite foi retirado do aquecimento e resfriado por meio de imersão em água gelada. Ao atingir temperatura próxima aos $40{ }^{\circ} \mathrm{C}$, foi adicionado $1 \%$ da cultura lática previamente preparada LyoFast $\left(\right.$ Sacco $\left.^{\circledR}\right)$, constituída por Lactobacillus bulgaricus e Streptococcus thermophilus, o qual foi levemente homogeneizado com o auxílio da função 'pulsar' de um liquidificador, com 4 a 6 repetições, e posteriormente incubado em temperatura entre $40-45^{\circ} \mathrm{C}$, durante 11 horas. Após este período, o iogurte recebeu 
a adição da polpa de morango (5\%), do corante vermelho de cochonilla $(0,3 \%)$ e do aromatizante artificial de morango $(0.1 \%)$. A homogeneização nesta etapa foi realizada com o auxílio de um mixer, até que o iogurte obtivesse um aspecto totalmente homogêneo, permanecendo em refrigeração de $7{ }^{\circ} \mathrm{C}$ durante 24 horas, até a realização das análises propostas.

Para o tratamento 2, após a pesagem dos ingredientes, procedeu-se com a incorporação de $10 \%$ do WPC com $35 \%$ de proteína ao leite semidesnatado ainda frio, por meio de uma leve mistura manual (um método de escolha por parte dos pesquisadores na tentativa de evitar qualquer possível desestruturação proteica inerente à um processo um pouco mais agressivo, como o mixer ou o liquidificador, por exemplo). Atingida completa dissolução da proteína, o leite, o açúcar e o estabilizante foram misturados e submetidos ao aquecimento até a marca $\operatorname{dos} 85^{\circ} \mathrm{C}$, quando foi resfriado a $40{ }^{\circ} \mathrm{C}$ por imersão em água fria, para posterior adição de $1 \%$ da mesma cultura lática. O leite foi levemente homogeneizado com auxílio da função 'pulsar' de um liquidificador, com 4 a 6 repetições, e posteriormente incubado em temperatura entre $40-45^{\circ} \mathrm{C}$, durante 11 horas. As etapas posteriores de preparação do iogurte e adição dos ingredientes restantes seguiram exatamente conforme o indicado no tratamento 1 .

\section{Avaliação físico-química e composição centesimal}

As amostras foram avaliadas, em triplicata, quanto à acidez, pelo método titulométrico, conforme descrito na Instrução Normativa $n^{\circ} 68$ (BRASIL, 2006) e a determinação do $\mathrm{pH}$ por meio do uso de $\mathrm{pHmetro}$ da marca Alpax ${ }^{\circledR}$, modelo Apa200. As análises para determinação da composição dos iogurtes (TI e T2) foram realizadas após 24 horas da fabricação, sendo elas: determinação de umidade em estufa, marca Fanem ${ }^{\circledR}$, modelo 515 , a $105 \pm 3{ }^{\circ} \mathrm{C}$ até peso constante, bem como de sólidos totais, calculados pela diferença a partir da umidade (ZENEBON et al., 2008). Também foi realizado o método gravimétrico para a determinação do resíduo por incineração (ou resíduo mineral fixo, RMF), em mufla dupla em alumínio, marca Magnos $^{\circledR}$, acoplada a um controlador modelo Novus N480D, a $550-570{ }^{\circ} \mathrm{C}$ (INSTITUTO ADOLFO LUTZ, 1985). O conteúdo proteico foi determinado pela avaliação do conteúdo de nitrogênio total, por meio da metodologia de Kjeldahl (\% N x 6,38) (ZENEBON et al., 2008). As gorduras totais foram determinadas pelo método com butirômetro Gerber (ZENEBO et al., 2008), e para a determinação do conteúdo de carboidratos totais, foi empregada a metodologia da redução das soluções de Fehling (INTITUTO ADOLFO LUTZ, 1985).

\section{Avaliação das propriedades reológicas}

As propriedades reológicas das amostras de iogurte foram mensuradas 24 horas após a sua fabricação, em viscosímetro, marca Rion $^{\circledR}$, modelo VT-04E e com rotor acoplado $\mathrm{n}^{\circ} 3$, em temperatura de $25 \pm 2{ }^{\circ} \mathrm{C}$, durante 20 segundos de rotação a 50 RPM, conforme as orientações do fabricante do aparelho contidas no manual de instruções, e direcionadas às amostras de iogurte.

\section{Avaliação sensorial}

A avaliação sensorial foi realizada após 24 horas da fabricação dos iogurtes, para verificar a aceitabilidade do consumidor pelo método da escala hedônica, estruturada de 09 pontos, variando entre o gostei muitíssimo (09) e desgostei muitíssimo (01). Participaram desta avaliação, um total de 80 julgadores não treinados, entre acadêmicos e colaboradores 
da UNIOESTE, os quais foram escolhidos por conveniência, abordados verbalmente e convidados a participar da análise sensorial, que foi concluída em etapa única. Do total de participantes, $21 \%$ foram do sexo masculino, apresentando média de idade de 24,7 anos, e $79 \%$ do sexo feminino, com idade média de 22,5 anos.

As amostras foram servidas em copo descartável de $50 \mathrm{~mL}$, contendo cerca de $25 \mathrm{~mL}$ de cada tratamento, sendo os provadores convidados a avaliar os atributos gerais referentes à aparência, sabor, aroma e consistência dos iogurtes. Cada tratamento foi codificado com números aleatórios de três dígitos. As notas recebidas foram submetidas ao teste de variância e também foram avaliadas quanto ao índice de aceitabilidade, verificado através de uma equação matemática, e expresso em percentual, em que $\mathrm{A}=$ nota dada ao produto, e $\mathrm{B}=$ nota máxima da escala hedônica (IA = $(\mathrm{Ax} 100) / \mathrm{B})$.

De forma complementar, o conjunto das aceitações atribuídas para cada tratamento foi avaliado com a finalidade de obtenção da aceitação geral para cada iogurte, e com isso, possibilitar a determinação do produto de maior aceitabilidade, considerando todos os atributos avaliados.

Este projeto foi submetido e aprovado pelo Comitê de Ética conforme parecer $n^{\circ}$ $467 / 2011$.

\section{Avaliação estatística}

A análise estatística dos resultados obtidos foi realizada por meio do Programa R i386 versão 2.15.0, software livre (THE R FOUNDATION, 2012), aplicando Análise de Variância (ANOVA) pelo teste de normalidade de Shapiro-Wilk.

\section{RESULTADOS E DISCUSSÃO}

\section{Análises físico-químicas}

Os resultados das análises físico-químicas dos iogurtes (tratamentos 1 e 2), seguidos dos valores padrão indicados pela legislação vigente estão apresentados na Tabela 1.

Em relação à acidez titulável, houve diferença significativa $(p<0,05)$ entre as médias dos tratamentos avaliados, tendo o T2 apresentado maior percentual de acidez titulável em comparação ao T1 provavelmente por influência da característica levemente ácida proveniente do WPC 35 (PAGE et al., 2004; OLIVEIRA et al., 2012; SOORO, 2013). Apesar disso, ambos os tratamentos estão de acordo com o parâmetro de acidez determinado pela Instrução Normativa $n^{\circ} 46$ (BRASIL, 2007), que oficializa os métodos analíticos para controle de leite e produtos lácteos.

Os dois tratamentos diferiram significativamente $(\mathrm{p}<0,05)$ nas medições de $\mathrm{pH}$, no entanto, a legislação não especifica a faixa ideal de medição para este índice. $\mathrm{O}$ aumento no teor proteico ao iogurte favoreceu a redução do valor de $\mathrm{pH}$, provavelmente devido ao teor de lactose (48\% a $52 \%$ ) contida no WPC 35 \% (PAGE, et al., 2004) que contribui no processo fermentativo para a maior produção de ácido láctico e consequente redução do pH, como verificado no T2. Resultado similar foi observado por Soares et al. (2011), que durante a vida de prateleira de iogurte integral detectaram o aumento da acidez titulável com consequente redução de $\mathrm{pH}$, em função da adição prévia de soro de leite. Esta análise por sua vez, se faz importante, pois iogurtes com elevado $\mathrm{pH}$ (acima de 4,6) tem estabilidade desfavorecida pela insuficiente formação do gel, e o iogurte com alta acidez (pH abaixo de 4,4) favorece a liberação do soro devido à contração do 
Tabela 1 - Resultados médios e desvios-padrão das análises de acidez, pH, viscosidade e composição centesimal dos dois tratamentos estudados ${ }^{1}$

\begin{tabular}{cccc}
\hline Análise & Tratamento 1 & Tratamento 2 & Padrão* \\
\hline Acidez titulável $(\% \mathrm{v} / \mathrm{m})$ & $0,79^{\mathrm{b}}( \pm 0,00)$ & $0,94^{\mathrm{a}}( \pm 0,09)$ & $0,6-1,5 \%$ \\
$\mathrm{pH}$ & $4,13^{\mathrm{a}}( \pm 0,06)$ & $3,93^{\mathrm{b}}( \pm 0,06)$ & $\mathrm{NE}$ \\
Viscosidade $(\mathrm{d}-\mathrm{Pas})$ & $8,00^{\mathrm{b}}( \pm 0,00)$ & $10,00^{\mathrm{a}}( \pm 0,00)$ & $\mathrm{NE}$ \\
Umidade $(\% \mathrm{~m} / \mathrm{m})$ & $83,29^{\mathrm{a}}( \pm 2,75)$ & $77,76^{\mathrm{b}}( \pm 3,36)$ & $\mathrm{NE}$ \\
Sólidos Totais $(\% \mathrm{~m} / \mathrm{m})$ & $16,7^{\mathrm{b}}( \pm 2,74)$ & $22,24^{\mathrm{a}}( \pm 3,35)$ & $\mathrm{NE}$ \\
Cinzas $(\% \mathrm{~m} / \mathrm{m})$ & $0,81^{\mathrm{b}}( \pm 0,03)$ & $1,17^{\mathrm{a}}( \pm 0,05)$ & $\mathrm{NE}$ \\
Proteínas $(\% \mathrm{~m} / \mathrm{m})$ & $3,49^{\mathrm{b}}( \pm 0,21)$ & $6,18^{\mathrm{a}}( \pm 0,05)$ & Mín. $2,9 \%$ \\
Gorduras $(\% \mathrm{~m} / \mathrm{m})$ & $2,70^{\mathrm{a}}( \pm 0,00)$ & $2,70^{\mathrm{a}}( \pm 0,00)$ & $0,6-2,9 \%$ \\
Carboidratos $(\% \mathrm{~m} / \mathrm{m})$ & $9,94^{\mathrm{b}}( \pm 1,85)$ & $13,58^{\mathrm{a}}( \pm 0,57)$ & $\mathrm{NE}$ \\
\hline
\end{tabular}

1 Valores médios das análises em triplicata de cada tratamento, seguidos do desvio-padrão. Médias seguidas de uma mesma letra nas linhas não diferem entre si ao nível de 5\% de significância pelo teste de Shapiro - Wilk. Tratamento 1: iogurte semidesnatado tradicional; Tratamento 2: iogurte semidesnatado obtido com WPC $35 \%$. * NE - Não estabelecido pela Legislação vigente.

coágulo e à baixa hidratação das proteínas (BRAGA et al., 2012).

Quanto à viscosidade, houve diferença significativa $(\mathrm{p}<0,05)$ entre os resultados médios dos dois tratamentos avaliados, sendo o T2 mais viscoso em relação ao iogurte tradicional em função da adição do WPC 35 \%, o qual é capaz de, entre outras características, atuar como agente doador de viscosidade (ANTUNES et al., 2003; PAGE et al., 2004), sendo um dos principais motivos de sua incorporação no produto. Este resultado assemelha-se ao obtido por Loures et al. (2010), que avaliaram a incorporação de concentrado proteico em iogurte diet de morango, e verificaram o aumento da consistência das amostras que receberam maiores concentrações de WPC. Do mesmo modo, Davanço et al. (2009) e Antunes; Fariña (2012) demonstraram que o tratamento térmico associado às proteínas do soro promoveram o aumento da capacidade de retenção de água dos iogurtes, pois favoreceu a reorganização das ligações entre as proteínas do soro e a caseína, gerando iogurtes de maior viscosidade e qualidade.
Não há, descrito na legislação, parâmetros para teores de umidade, sólidos totais e cinzas direcionados a este derivado lácteo. Destas determinações, todas diferiram significativamente entre as médias obtidas $(\mathrm{p}<0,05)$. Em relação aos resultados alcançados para umidade, estes estão acima do que foi descrito por Sampaio et al. (2011), ao estudarem as características físico-químicas do iogurte grego. Estes autores encontraram teor de umidade de $66,96 \pm 1,59 \%$, o que em parte pode ser justificado em função da maior quantidade de sólidos totais no iogurte grego, já que a concentração de açúcar é maior (14\%) do que a considerada na presente pesquisa (8\%), e da incorporação de cappuccino solúvel (5\%), ingredientes que promovem a redução do teor de água no produto final. No entanto, estes mesmos autores encontraram resultados semelhantes e proporcionais para sólidos totais, cinzas e também proteínas, as quais terão os resultados detalhadas adiante. Houve aumento do percentual de sólidos totais na amostra que recebeu o WPC $35 \%$, e este resultado, segundo o estudo da influência da adição de espessantes e leite em pó em 
iogurtes desnatados, conforme observado por Teles; Flôres (2007), culmina novamente no aumento da viscosidade do iogurte. Do mesmo modo, a adição do WPC $35 \%$ no T2 explica o menor teor de umidade e maior de sólidos totais e cinzas, como também foi determinado por Aziznia et al. (2008), ao estudarem o efeito de whey protein e goma adragante como substituintes de gordura em iogurtes desnatados.

Ramos et al. (2009) ao estudarem o perfil de textura do iogurte grego indicou o valor aproximado de $24 \%$ de sólidos totais, juntamente com $10 \%$ de gordura para a obtenção da consistência que caracteriza este produto. Este resultado vai de encontro ao obtido na presente pesquisa, para sólidos totais, a qual determinou teor muito próximo $(22,24 \%)$ no iogurte que recebeu adição de concentrado proteico.

De acordo com a Instrução Normativa $\mathrm{n}^{\mathrm{o}} 46$ (BRASIL, 2007), os iogurtes devem cumprir o requisito mínimo de $2,9 \%$ de proteínas. Desta forma, como já esperado, a incorporação do teor proteico no T2 demonstrou diferença significativa entre as médias avaliadas $(\mathrm{p}<0,05)$, assim como o resultado verificado por Aziznia et al. (2008), que ao variar a concentração de WPC em iogurtes desnatados, determinaram o aumento proporcional do teor proteico nas análises realizadas. Sendo assim, os resultados obtidos na pesquisa encontram-se dentro do parâmetro especificado pela legislação, a qual não estabelece limite máximo para tal constituinte.

Ainda, em relação às gorduras totais, ambos os resultados obtidos estão dentro da especificação para iogurtes semidesnatados ( $\leq 2,9 \%$ ), conforme Brasil (2007), não havendo diferença significativa $(\mathrm{p}>0,05)$ entre as médias determinadas, porque, assim como descrito por Sooro (2013) e Page et al. (2004), o concentrado proteico possui cerca de $3 \%$ de gorduras em sua composição, porém tal quantidade não é capaz de causar diferença aparente na determinação realizada em butirômetro.

Os valores encontrados na pesquisa de carboidratos, tanto para o T1 quanto para o T2 diferiram significativamente $(\mathrm{p}<0,05)$ entre as médias dos resultados obtidos, sendo o T2 o iogurte com maior teor deste constituinte. Esta determinação ocorreu, em função da sacarose e da polpa de morango adicionados aos tratamentos, e somado ao fato, no segundo caso, ao WPC $35 \%$ incorporado, que contribui para o aumento no teor de lactose. Teor semelhante foi descrito por Bastiani (2009), que desenvolveu e caracterizou iogurtes desnatados adicionados de $1,5 \%$ de concentrado proteico de soro e farinha de linhaça.

\section{Análise sensorial}

Quanto à análise sensorial (Tabela 2), as duas formulações obtiveram boa aceitação em todos os atributos avaliados, exceto para o fator consistência, referente ao T1, o qual recebeu nota média de 5,98, ou seja, entre 5 - não gostei nem desgostei e 6 - gostei. Os demais atributos apresentaram médias entre 7 - gostei pouco e 8 - gostei muito, o que demonstra boa aceitação das formulações pelos provadores.

$\mathrm{O}$ atributo aparência, assim como a consistência, apresentaram diferença significativa $(\mathrm{p}<0,05)$ entre as médias avaliadas para os dois tratamentos, sendo que ambas as características indicaram a maior preferência para o T2. Loures et al. (2010), ao analisarem sensorialmente iogurtes diet de morango adicionados com diferentes concentrações de concentrado proteico de soro, verificaram que o aumento da matéria sólida aumentou proporcionalmente a consistência dos iogurtes, bem como a preferência na avaliação sensorial. Em outro estudo de sinérese, textura e análise sensorial de iogurtes desnatados probióticos adicionados de concentrado 
proteico, Antunes et al. (2004), também concluíram que a suplementação com WPC tendeu a conferir iogurtes mais firmes, gomosos e com maior capacidade de reter o soro, e que, devido a tais características, também foram sensorialmente preferidos.

Antunes et al. (2003), ao determinarem a necessidade de uma concentração mínima de proteínas (6-12\%) para a o processo de gelatinização do WPC, realçam o papel deste derivado lácteo em melhorar o aspecto dos alimentos. Estas e outras características tecnológicas também são descritas por Antunes (2003), que explica a maior aceitação dos produtos que recebem adição deste concentrado de proteínas.

Estes fatos confirmam o resultado alcançado na presente pesquisa, uma vez que o menor percentual de aceitação obtido foi para o atributo consistência do tratamento que não recebeu adição de fonte proteica, ou seja, pode-se entender que a preferência dos provadores esteve voltada ao iogurte de maior consistência.

Não houve diferença significativa $(p>0,05)$ entre as médias obtidas para os atributos sabor e aroma. Este dado representa boa aceitação de ambos os tratamentos, e mostra a viabilidade do processo produtivo, uma vez que não houve reprovação quanto ao sabor do iogurte adicionado de concentrado proteico. Complementando tal resultado, em estudo sensorial anterior descrito por Antunes; Fariña (2012), por meio da comparação entre iogurtes integrais adicionados de concentrado proteico frente ao soro em pó, demonstraram maior preferência sensorial pelo iogurte adicionado do derivado proteico em sua forma concentrada, além de terem determinado a melhor condição do tratamento térmico para o alcance da consistência mais aceitável $\left(85^{\circ} \mathrm{C}\right)$, assim como desenvolvido neste trabalho, reforçando a aplicabilidade destas condições no processamento de produtos lácteos, ao relacionar estas determinações.

Portanto, considerando todos estes índices, a aceitabilidade geral obtida pela avaliação de todos os atributos relativos a cada tratamento, e, ao nível de $5 \%$ de probabilidade, apresentou diferença significativa entre as médias dos resultados avaliados, e, desta forma, a aceitabilidade média geral demonstrou ser maior para o T2, ou seja, de $83,12 \%( \pm 16,41)$, em detrimento da obtida para o $\mathrm{T} 1$, de $76,65 \%( \pm 17,43)$. Este resultado permite relacionar tal índice pela adição do WPC $35 \%$ ao iogurte, que modificou e aprimorou algumas características do produto quando comparado ao T1, e promoveu, por consequência, a maior preferência sensorial.

Tabela 2 - Resultados médios da análise sensorial das formulações de iogurte e índice de aceitação (IA) 1

\begin{tabular}{ccccccccc}
\hline \multirow{2}{*}{ Trat } & \multicolumn{2}{c}{ Aparência } & \multicolumn{2}{c}{ Sabor } & \multicolumn{2}{c}{ Aroma } & \multicolumn{2}{c}{ Consistência } \\
\cline { 2 - 8 } & IA (\%) & Média & IA $(\%)$ & Média & IA $(\%)$ & Média & IA (\%) & Média \\
\hline 1 & $80,30^{\mathrm{b}}$ & $7,21^{\mathrm{b}}$ & $80,98^{\mathrm{a}}$ & $7,28^{\mathrm{a}}$ & $78,80^{\mathrm{a}}$ & $7,08^{\mathrm{a}}$ & $66,39^{\mathrm{b}}$ & $5,98^{\mathrm{b}}$ \\
& $( \pm 16,37)$ & $( \pm 1,47)$ & $( \pm 15,81)$ & $( \pm 1,42)$ & $( \pm 15,69)$ & $( \pm 1,41)$ & $( \pm 17,94)$ & $( \pm 1,61)$ \\
2 & $86,39^{\mathrm{a}}$ & $7,76^{\mathrm{a}}$ & $78,46^{\mathrm{a}}$ & $7,05^{\mathrm{a}}$ & $78,50^{\mathrm{a}}$ & $7,05^{\mathrm{a}}$ & $89,13^{\mathrm{a}}$ & $8,01^{\mathrm{a}}$ \\
& $( \pm 13,14)$ & $( \pm 1,18)$ & $( \pm 18,36)$ & $( \pm 1,65)$ & $( \pm 16,95)$ & $( \pm 1,53)$ & $( \pm 14,09)$ & $( \pm 1,27)$ \\
\hline
\end{tabular}

${ }^{1}$ Valores médios das análises em 80 repetições, seguidos do desvio padrão. Médias seguidas por uma mesma letra nas colunas não diferem entre si ao nível de $5 \%$ de significância pelo teste de Shapiro - Wilk.

Tratamento 1: iogurte semidesnatado tradicional; Tratamento 2: iogurte semidesnatado obtido com WPC $35 \%$. 


\section{CONCLUSÕES}

É possível obter um iogurte semidesnatado, sabor morango e adicionado de WPC $35 \%$, com características físico-químicas capazes de atender aos parâmetros dispostos em legislação, além de ter alcançado aceitabilidade geral superior à do iogurte tradicional, ausente de suplementação proteica.

Sendo assim, considerando que os atributos de aparência e consistência, além de sabor e aroma, atingiram boa aceitação, e que estes são parâmetros apreciados pelos consumidores, podendo determinar o consumo deste derivado lácteo, a utilização do concentrado proteico na fabricação de iogurte demonstra ser viável e benéfica no âmbito tecnológico, o que justifica a sua incorporação aos alimentos, apesar desta adição representar custo de produção superior ao iogurte tradicional.

O produto desenvolvido representa ainda, um destino sustentável ao coproduto agroindustrial, evitando o seu descarte no meio ambiente ao utilizar suas potencialidades de forma inteligente e inovadora quando aplicadas aos alimentos.

\section{REFERÊNCIAS}

Antunes, A. E. C.; CAZETtO, T. F.; BOLLINI, H. M. A. Iogurtes desnatados probióticos adicionados de concentrado proteico do soro de leite: Perfil de textura, sinérese e análise sensorial. Alimentos e Nutrição, v. 15, n. 2, p. 107-114, 2004.

Antunes, A. E. C.; MOTtA, E. M. P.; ANTUNES, A. J. Perfil de textura e capacidade de retenção de água de géis ácidos de concentrado proteico de soro de leite. Ciência e Tecnologia de Alimentos, v. 23, suppl. 0, p. 183-189, 2003.

Antunes, A. J. Funcionalidade de Pro- teínas do Soro de Leite Bovino. Barueri: Manole, 2003. 150 p.

ANTUNES, A. R.; FARIÑA, L. O. Iogurte adicionado de WPC ou soro em pó: Qual a melhor opção sensorial. In: SEMANA DE ENGENHARIA E TECNOLOGIA DE ALIMENTOS, 2., 2012, Umuarama. Anais... Umuarama: UEM, 2012. p. 44-48.

AZIZNIA, S. et al. Whey protein concentrate and gum tragacanth as fat replacers in nonfat yogurt: chemical, physical, and microstructural properties. Journal of Dairy Science, v. 91, n. 7, p. 2545-2552, 2008.

BASTIANI, M. I. D. Iogurte adicionado de concentrado proteico de soro de leite e farinha de linhaça: desenvolvimento, qualidade nutricional e sensorial. 2009. 95 p. Tese (Doutorado em Ciência e Tecnologia de Alimentos) - Universidade Federal de Viçosa, Viçosa, 2009.

BRAGA, A. C. C.; NETO, E. F. A.; VILHENA, M. J. V. Elaboração e caracterização de iogurtes adicionados de polpa e de xarope de mangostão (Garcinia mangostana L.). Revista Brasileira de Produtos Agroindustriais, v. 14, n. 1, p. 77-84, 2012.

BRASIL. Ministério da Agricultura, Pecuá-ria e Abastecimento. Instrução Normativa $\mathrm{n}^{\circ} 68$, de 12 de dezembro de 2006. Oficializa os métodos analíticos oficiais físico-químicos, para controle de leite e produtos lácteos. Diário Oficial da República Federativa do Brasil, Brasília, 14 dez. 2006. Seção 1, p. 8.

BRASIL. Ministério da Agricultura, Pecuária e Abastecimento. Instrução Normativa $n^{\circ} 46$, de 23 de outubro de 2007. Aprova o Regulamento Técnico de Identidade e Qualidade de Leites Fermentados. Diário 
Oficial da República Federativa do Brasil, Brasília, 24 out. 2007. Seção 1, p. 5.

BRASIL. Ministério da Agricultura, Pecuária e Abastecimento. Instrução Normativa $\mathrm{n}^{\circ}$ 62, de 29 de dezembro de 2011. Aprova o Regulamento Técnico de Identidade e Qualidade do Leite tipo A, o Regulamento Técnico de Identidade e Qualidade de Leite Cru Refrigerado, o Regulamento Técnico de Identidade e Qualidade de Leite Pasteurizado e o Regulamento Técnico da Coleta de Leite Cru Refrigerado e seu Transporte a Granel, em conformidade com os Anexos desta Instrução Normativa. Diário Oficial da República Federativa do Brasil, Brasília, 30 dez. 2011. Seção 1, p. 6.

COELHO, D. R.; GIGANTE, E. L. Aplicação de transglutaminase na fabricação de iogurte. In: CONGRESSO DE INICIAÇÃO CIENTÍFICA DA UNICAMP, 18., 2010, Campinas. Anais... Campinas: UNICAMP, 2010 .

CREDIDIO, E. Leite: O elixir da vida. Itu: OTTONI, 2008, 27 p.

DAVANÇO, F. V. et al. Avaliação do efeito do tratamento térmico na capacidade de retenção de água do iogurte através da metodologia de superfície de resposta. Revista Instituto de Laticínios Cândido Tostes, v. 64, n. 369, p. 3-7, 2009.

GHALY, A. E.; KAMAL, M. A. Submerged yeast fermentation of acid cheese whey for protein production and pollution potential reduction. Water Research, v. 38, n. 3, p. 631-644, 2004.

HARAGUCHI, F. K.; ABREU, W. C.; PAULA, H. Proteínas do soro do leite: composição, propriedades nutricionais, aplicações no esporte e benefícios para a saúde humana. Revista de Nutrição, v. 19, n. 4, p. 479-488, 2006.

INSTITUTO ADOLFO LUTZ. Normas Analíticas do Instituto Adolfo Lutz. v. 1: Métodos químicos e físicos para análise de alimentos. 3. ed. São Paulo: IMESP, 1985. p. 27-28.

LEINDECKER, G. C. Separação das proteínas do soro de leite in natura por ultrafiltração. 2011. 48 p. Trabalho de diplomação (graduação em Engenharia Química) Universidade Federal do Rio Grande do Sul, Porto Alegre. 2011.

LOURES, M. M. R. et al. Análise descritiva por ordenação na caracterização sensorial de iogurte diet sabor morango enriquecido com concentrado proteico do soro. Semina: Ciências Agrárias, v. 31, n. 3, p. 661-668, 2010.

OLIVEIRA, D. F.; BRAVO, C. E. C.; TONIAL, I. B. Soro de leite: um subproduto valioso. Revista do Instituto de Laticínios Cândido Tostes, v. 67, n. 385, p. 64-71, 2012.

PAGE, J. et al. Manual de referência para produtos de soro e lactose dos EUA. São Paulo: U.S. DAIRY EXPORT COUNCIL, 2004. 226 p.

PAGNO, C. H. Development of food thickner for liquids with aggregated nutritional value intended for dysphagic individuals. 2009. 80 p. Master dissertation (Master's Degree in Food Science and Technology) - Institute of Food Science and Technology, Federal University of Rio Grande do Sul, 2009.

RAMOS, T. M. et al. Perfil de textura de Labneh (iogurte grego). Revista do Instituto de Laticínios Cândido Tostes, v. 64, n. 369, p. 8-12, 2009 . 
SAMPAIO, A. P. A. M. et al. Elaboração e caracterização físico-química de iogurte grego sabor cappuccino. Revista Higiene Alimentar, v. 25, mar/abr., 2011. Disponível em: <http://www.sovergs.com.br/site/ higienistas/trabalhos/10775.pdf $>$. Acesso em: 20 ago. 2014.

SOARES, D. S. et al. Aproveitamento de soro de queijo para produção de iogurte probiótico. Arquivo Brasileiro de Medicina Veterinária e Zootecnia, v. 63, n. 4, p. 996-1002, 2011.

SOORO. Concentrado Indústria de Produtos Lácteos Ltda. Produtos: WPC - Aplicações, 2013.
TELES, C. D.; FLÔRES, S. H. Influência da adição de espessantes e leite em pó nas características reológicas do iogurte desnatado. Boletim do Centro de Pesquisa de Processamento de Alimentos, v. 25, n. 2, p. 247-256, 2007.

THE R FOUNDATION FOR STATISTICAL COMPUTING. R version 2.15 .0 (2012-0330). 2012.

ZENEBON, O.; PASCUET, N. S.; TIGLEA, P. Métodos físico-químicos para análise de alimentos. IV edição, $1^{\mathrm{a}}$ edição digital. Instituto Adolfo Lutz, São Paulo, 2008. $1020 \mathrm{p}$. 